\title{
Network Capability, Innovation Strategy, and Innovation Performance
}

\author{
He Jianhong, Bai Yusong, Zhang Shiyun \\ School of Economics and Management, Chongqing University of Posts and Telecommunications, Chongqing, P.R.China
}

Email address:

hejh@cqupt.edu.cn (He Jianhong),38944276@qq.com (Bai Yusong), zhangsy@cqupt.edu.cn (Zhang Shiyun)

\section{To cite this article:}

He Jianhong, Bai Yusong, Zhang Shiyun. Network Capability, Innovation Strategy, and Innovation Performance. American Journal of Theoretical and Applied Business. Vol. 2, No. 3, 2016, pp. 13-19. doi: 10.11648/j.ajtab.20160203.11

Received: September 7, 2016; Accepted: October 28, 2016; Published: November 25, 2016

\begin{abstract}
Based on a literature review, this paper classifies network capability into network vision capability, network constructing capability, and network management capability and constructs a model with explorative innovation and exploitative innovation being the mediating variables to analyze the influence of the three dimensions of network capabilities on innovation performance. We obtain 257 effective samples through questionnaire and verify every influencing path. Our findings show that the three dimensions of network capability have a positive effect on innovation performance, clear innovation strategy helps to improve innovation performance, different network capability structures result in different innovation strategy forms, and false innovation strategy forms weaken the effect of network capability on innovation performance.
\end{abstract}

Keywords: Analysis Network Capability, Explorative Innovation, Exploitative Innovation, Innovation Performance

\section{Introduction}

It follows from existing literature that it has been widely recognized that network capability has a positive effect on innovation performance (Joe Tidd, 2006). However, there is no consensus on the path along which network capability influences innovation performance. Some scholars introduced structural attribute, relation strength, organizational learning, and sourcing as mediating variables to observe the mechanism of network capability influencing innovation performance (Walter A., et al., 2006), but no scholars have studied the role of innovation strategy in such process in depth, and empirical proof is particularly lacking. For this reason, this paper attempts to introduce the innovation strategy form as the mediating variable and construct a relation model among network capability, innovation strategy, and innovation performance to empirically explore the path of innovation performance. This paper may have the following theoretical contributions. Firstly, this paper selects the innovation strategy as the mediating variable to reveal the effect direction of various dimensions of network capability on innovation strategy, explore in depth the path and mechanism by which network capability influences innovation performance via innovation strategy, and illustrate the reason why network capability is strengthened sometimes but weakened in other time. Secondly, our empirical findings prove that network capability is correlated negatively to explorative strategy and positively to exploitative strategy, expanding the research on the relationship between network capability and innovation manner. Besides, our findings show that firms need to grasp the fit between strategy and capability and select proper innovation manners based on a clear definition of internal resource and capability endowment characteristics to effectively improve innovation performance with their own capability elements, a finding being of strong realistic significance for the proper utilization of resources and capabilities and for the comprehensive improvement of innovation levels.

\section{Research Hypotheses}

\subsection{Formation of Network Capability and Innovation Performance}

Network capability influences innovation performance through three dimensions which show strong independence, so we will respectively discuss the effects of network capability on innovation performance from these three dimensions. 
Firstly, network vision capability, the firm's strategic capability of managing its network, without which the firm can hardly discover the valuable innovative opportunities and activities embedded in the strategic network structure (Kristian M., et al., 2005), manifests the focus firms' recognition and understanding of the network environment in which it is located and is the basis on which it acts on and responds to the network change. Firms with stronger network vision capabilities are more likely to improve their position center degree in the network and thus improve its degree of obtaining and controlling resources(Elsebeth H. et al., 2003), i.e., strong and significant network vision capability may probably bring in results as follows: (1) more timely and comprehensive obtaining and control of innovation-related new information which is important for selecting proper innovation direction and resolving process design problems; (2) innovative activities being more network-oriented. The firm is willing to facilitate innovative activities through external technological knowledge resources, so it may establish flexible internal organizational structure and innovation incentive mechanism to enable departments of product design, production, and marketing to communicate more conveniently with the outside world; and (3) possession of more structural holes. The firm possesses more non-redundant heterogeneous connection, so it can conveniently learn about the qualification of its potential partners, more quickly know opportunities or threats, and obtain and select differentiating information and thus implement innovative activities more quickly and improve the success possibility of innovation(Brian Uzzi., 2008)]. Based on the above analysis, we propose the following hypotheses:

H1a: Network vision capability has a positive effect on innovation performance.

Secondly, network constructing capability refers to the firm's capability to choose, initiate and adjust the network relationships. Firms with a network constructing capability can choose potential network partners according to their own development state and demand, and then establish the network relationships which the firms expect. It is the relationship that determines the flowing direction and efficiency of the firm's resources. Therefore, network constructing capability helps the firm to mobilize and directly absorb other movers' resources and abilities before improving its resource basis to innovate and form the firms' product, process and management innovation so as to improve the internal innovation process and management flow (Gautam A., 2000), promote the formation and optimization of the firm' internal management system. In addition, the network constructing capability also helps the firm to obtain and absorb its partners' experience and knowledge and then form the basis for learning other firms' organization innovation practice. Based on the above analysis, we propose the following hypothesis:

H1b: Network constructing capability has a positive effect on corporate innovation performance

Thirdly, the intention and possibility to maintain, adjust and transform the existing relationship is core to network management. The focus firm's initiative to start network management in the network helps to promote its interaction with its partners, strengthen the cooperation among the firms (Ritter W. 2002; J Udith Behrens, 2016), increase the relationship embedded of firm in the network and form their strong relationship tie with its partners (Brass D. et al. 2004). Firstly, this strong relationship network helps to improve the focal firms' trust with their partners and reduce the cost of resources' acquisition; Secondly, when the firm builds a high strong relationship with organizations which have good social prestige through the network management capability, the firms has the bridge and tunnel of a broader relationship, which helps it to approach new customers or new partners more easily, and then get the operational resources necessary for innovation activities such as financial, human and capital, and has the basis that directly promotes its innovative products to non-technical clients (Ritter T. 2003); Thirdly, the tacit knowledge cannot be encoded, so a strong relationship link is needed to convey in the network. Network management capabilities and strong relation networks enable the tacit knowledge to be transferred smoothly, and the firm can obtain the tacit knowledge exchange advantage. Based on the above analysis, we propose the following hypothesis:

H1c: Network management capability has a positive effect on innovation performance

\subsection{Innovation Strategy and Performance}

Although some research based on two dimensions- time of sustainable innovation and degree of cooperation among organizations, the innovation strategy could be divided into four basic types: the independently initiative innovation, the independently imitative innovation, the collaboratively initiative innovation, and the collaboratively imitative innovation. The independently initiative innovation and the collaboratively initiative innovation enable the firm to obtain the required information and knowledge in an explorative way, while the independently imitative innovation and the collaboratively imitative innovation make the firm obtain the information and knowledge necessary for technological innovation in the following or learning way. Thus, we can use "exploratory innovation" and "exploitative innovation" to define the type of innovation strategy (Jansen P. et al. 2006). Based on this classification, the type of innovation strategy has a clear structure relationship with innovation performance and has an effect on the configuration of firm resources and innovation elements as well as the formation of technology innovation performance (He Z, Wong P. 2004; Stefan Kirchner, 2016). Innovation strategies with more adventurous and open spirits and stronger willingness to cooperate are able to obtain the market information resources and technical resources more quickly, making up for the inadequacy of internal innovation resources and then improving the innovation performance. Moreover, Ha Hoang, et al. (2010) empirically proves that no matter we adopt which kind of innovation strategy form, a clear innovation strategy is the key factor which affects the formation of innovation performance. A firm with high innovation performance has a clearer and more consistent strategic guidance than that with lower 
innovation performance. The firm selects either the exploratory innovation or the exploitative innovation, and if you try to use the two strategies simultaneously, its effect on innovation is negative (Benner M. et al. 2003).

$\mathrm{H} 2$ : Both explorative innovation and exploitative innovation strategies have a positive effect on innovation performance

\subsection{Network Capability and Selection of Innovation Strategy}

It follows from existing literature that many studies argue that the effect of the network capability on the result of innovation is partly due to mediating variables such as the structure characteristic of network and the way to get resources. However, no research sets the innovation strategy or mode as a mediating variable. As the firm selects its innovation strategy based on its existing capability structure, any factor in the firm's combination of capability elements may affect the choice of the strategy form. This paper argues that the effect of the network capability on the innovation performance is partly due to the innovation strategy which plays a mediating role between the network capability and the innovation performance, so we need to discuss the effect of the network capability on the innovation strategy.

In fact, there is coupling between the strength relationship due to different network capability and technological innovation model. It also illustrates that firm's choice of innovation strategy is decided by its network capability. First of all, from the perspective of structural embeddedness, a stronger network vision capability makes the firm in the center of the network, thus the firm can obtain redundant information, advantageous for the exploitative innovation, while a weaker network vision capability makes the firm in a subordinate and following status in the network an advantage for the explorative innovation due to the firm's capability of obtaining the heterogeneous information (Koka B. et al. 2008; Sharon Belenzon, Mark Schankerman, 2015). Secondly, from the perspective of the strength of relationship link, due to low cost and low information redundancy, weak relationships based on low network management capability is advantageous for exploratory innovation, while strong relationships based on strong network capability is able to convey complex knowledge based on trust among firms, beneficial to exploitative innovation. Such argument was illustrated in empirical study of Justin J. et al. (2009): As for an exploitative learning and exploitative innovation strategy, the strong link based on network management capability is positively related to organizational performance. In terms of an exploratory innovation strategy, the strong link based on network management capability is unable to meet the requirements of firms to the creative knowledge, thus it is negatively related to organizational performance, but the weak link is positively related to organizational performance. That is to say, the closely connected network caused by the strong network capability is suitable for gradual innovation but unsuitable for fundamental innovation. Thirdly, strong network management capability enables firms in the network to use formal and more legally binding structure, so cooperation among the firms in the network becomes long-term. Hence, the firm's innovation activities are easy to gain support from the network, so it is more suitable for the firm to adopt exploitative innovation characterized by learning and absorption (Koen D., Geert D., 2007). If the network constructing capability of the focal firm is low and lacks strong code of conduct between partners, it is easy to form a low efficient network characterized by loose relationship, low link density, and long average path due to poor link intensity. Such network makes the differences among the network members more prominent, and the firm has easier access to heterogeneous information. They are not bound by the strict rules of communication among firms and are highly free to choose the innovation direction, thus it is suitable for exploratory innovation. Based on the above analysis, we propose the following hypotheses:

H3: Network capability has a significant effect on the selection of innovation strategy form.

H3a: Network has a positive correlation to exploitation strategy and a negative correlation to exploration strategy.

\section{Variable Desisgn and Measurement}

\subsection{Measurement of Innovation Performance}

For the choice of innovation performance measurement indicators, Gert, Ritter Human (2009) argue that the measurement of innovation performance depends mainly on the ratio of innovation output to the overall corporate output. Indicators, such as the ratio of new product sales income and the proportion of the innovation product and process innovation, should be used,. The Oslo manual (OECD, 1992) also points out that the rate of innovation is a better measurement indicator of innovation performance which has been widely used in research on innovation performance in western countries and China. Therefore, this study used three indicators to measure the firm' innovation performance, i.e., the invention quantity of authorized patent per one thousand R\&D professionals, the proportion of new products sales revenue to the total sales revenue, and the overall labor productivity (the ratio of the firm's added value to the number of the firm staff per year). We make the indicators into Likert 5.0 subscales, and the scale calibration is "whether or not the following description is consistent with the real situation of your company: 1 stands for "very agreealbe", and 5 stands for "strongly disagreeable".

\subsection{Measurement of Network Capability}

Based on Ritter and Bonner, et al. (2005), we measure network vision capability with three dimensions- network awareness, recognition, and positioning and design eight indicators; We measure network constructing capability with three variables-selection of partners, relationship initiating and adjustment; We use the measurement methods of Gert, Ritter Human (2009) and Bonner, et al. (2005) for reference, and measure network management capability with four variables-coordination of relationship, organization of 
relationship, exchange of relationship, and control of relationship. All the variables are made into the questionnaire items in the form of Likert5.0, and the scale calibration is "whether or not the following description is consistent with the real situation of your company: 1 stands for "very inconsistent", 5 stands for "suitable".

\subsection{Measurement of Innovation Strategy}

In this paper, we use "exploratory innovation" and "exploitative innovation" to define the type of firm's innovation strategy and select the items suitable for domestic firms and industries from the questionnaire by Jansen, et al. (2006), He \& Wong (2004). At the same time, according to the opinions of the experts, when we make the preliminary research, we adjust the representing way of items and make the formal items and then make them into Likert 5.0 subscales and the scale calibration is "whether or not the following description is consistent with the real situation of your company: 1 stands for "very inconsistent", 5 stands for "suitable".

\section{Empirical Analysis}

\subsection{Questionnaire Survey}

In formal study, two ways are adopted to collect data: First, holders of a MBA or EMBA who graduated from universities in Chongqing, Tianjin, Guangzhou, and Chengdu are regarded as the object of the questionnaire survey, and questionnaires are issued and recycled via email and field survey; Second, questionnaires are collected in a rolling snowball form through the social relationship network of our team members. The respondents of our survey consist of senior and chief executives, first-line managers, and senior technical developers. In the research we sent 380 questionnaires and recycled 284 ones. 5 questionnaires are eliminated because their data can't be processed, so we actually recycled 279 effective ones. In order to ensure that the respondents have an accurate understanding of the questionnaire items and give answers according to the reality of their firms, we made strict screening of recycled questionnaires. Major screening criteria are made as follows: (1) the questionnaire respondents need to be top or middle managers in a firm; (2) the firm's survived more than 10 years; (3) the monopoly firms shall be excluded. After screening, 22 recycled questionnaires are excluded because they do not meet the requirements. Thus, 257 valid samples are finally selected into the research. From the perspective of industrial structure, the sample firms have covered the construction, manufacturing, retail, medicine, real estate, catering, and so on. Therefore, as a whole, this study samples, though not randomly sampled, are highly representative and cover a wide range of areas and industries, meeting our research requirements.

\subsection{Factor, Reliability, and Validity Analysis}

First, we conducted an exploratory factor analysis using SPSS17.0 software and verified the validity of measurement data, and at the same time we conducted the reliability test combining AMOS7.0. The results show that the KMO value is 0.815 , and the Bartlett test value is significantly different from 0 . The two test results show that the sample data are suitable for factor analysis. Data were collected mainly according to the attitude of the subjects, so it is more suitable to use Cronbach alpha coefficient to examine the reliability of the questionnaire. According to Wortzel's research, when the Cronbach alpha coefficient is greater than 0.7 , it means high reliability; when it is less than 0.35 , it will lose value. It follows from Table 1 that the Cronbach alpha coefficient of each factor is preferred over the suggested value of 0.7 , suggesting that the scale is of good internal consistency. In terms of the validity test, most of our used questionnaire items come from the existing literature. When we design the items, we have fully consulted experts. Thus, the questionnaire is of good content validity. At the same time, the confirmatory factor analysis shows that every factor load is greater than 0.7 , indicating that the validity of the questionnaire is ideal.

Table 1. The scale's values of factor load and Cronbach's Alpha.

\begin{tabular}{|c|c|c|c|c|}
\hline Latent variable & Standard load & Cronbach $\alpha$ & reliability & Variation explanation \\
\hline Network perception (3) & .817 & .789 & \multirow{3}{*}{.896} & \multirow{3}{*}{.749} \\
\hline Network recognition (3) & .803 & .863 & & \\
\hline Network positioning (2) & .843 & .856 & & \\
\hline Partner selecting (3) & .861 & .865 & \multirow{3}{*}{.925} & \multirow{3}{*}{.657} \\
\hline Relationship initiating (4) & .882 & .917 & & \\
\hline Relationship adjustment (3) & .871 & .906 & & \\
\hline Relationship coordination (3) & .775 & .752 & \multirow{3}{*}{.869} & \multirow{3}{*}{.663} \\
\hline Relationship exchange (5) & .796 & .836 & & \\
\hline Relationship control (3) & .843 & .829 & & \\
\hline Explorative innovation (3) & & .762 & .932 & .753 \\
\hline Exploitative innovation (4) & & .865 & .872 & .698 \\
\hline Innovation performance (3) & & .837 & .865 & .834 \\
\hline
\end{tabular}

Based on the above theoretical assumptions and designed scale, this paper regards network vision ability, network constructing ability, and network management capability as a second-order factor. After the data is conducted a second-order confirmatory factor analysis (CFA), the fit indexes are: $2 / \mathrm{df}=1.87$, RMSEA $=0.032$, GFI $=0.93, \mathrm{CFI}=0.92$, IFI $=0.94$. As shown in Table 2 , the standardized load values of the second-order factor exceed 0.7 , Cronbach alpha also exceed the ideal value of 0.7 , and all of the combined reliability coefficients of the second-order factor exceed 0.8 , indicating that the first-order factor shows good 
internal consistency, the second order factor model is of enough convergent validity, 15 first-order factors are suitable for measuring the four second-order factors.

\subsection{Path Analysis and Hypothesis Test}

We tested the theoretical model of partial intermediary as shown in Figure 1 using AMOS. At the same time, in order to test the intermediary effect of innovation strategy on network capability and innovation performance, we also analyzed the direct effect model of network capability and innovation performance as well as the fit results of the intermediation model, which failed to consider the direct effect. We selected the best model after a comparison among the three models. The fit results of these models are shown in Table 2.

Table 2. Comparison among the models'fit indexes.

\begin{tabular}{lllllll}
\hline Index & $\boldsymbol{\chi 2}$ /df & GFI & AGFI & IFI & CFI & RMSEA \\
\hline Direct effect model & 1.936 & 0.953 & 0.913 & 0.924 & 0.931 & 0.043 \\
Partial intermediary model & 1.89 & 0.934 & 0.947 & 0.931 & 0.958 & 0.039 \\
Complete intermediary model & 2.34 & 0.893 & 0.923 & 0.895 & 0.882 & 0.057 \\
\hline
\end{tabular}

As can be seen from Table 2, the fit results of the direct effect model and partial intermediary model are ideal, but the values of most indicators in the partial intermediary model are better. More importantly, in further path analysis, the relationships among latent variables in the partial intermediary model are more significant, so we select the partial intermediary model as the final model. In this model, various standardized coefficients of the relationships are shown in Figure 1.

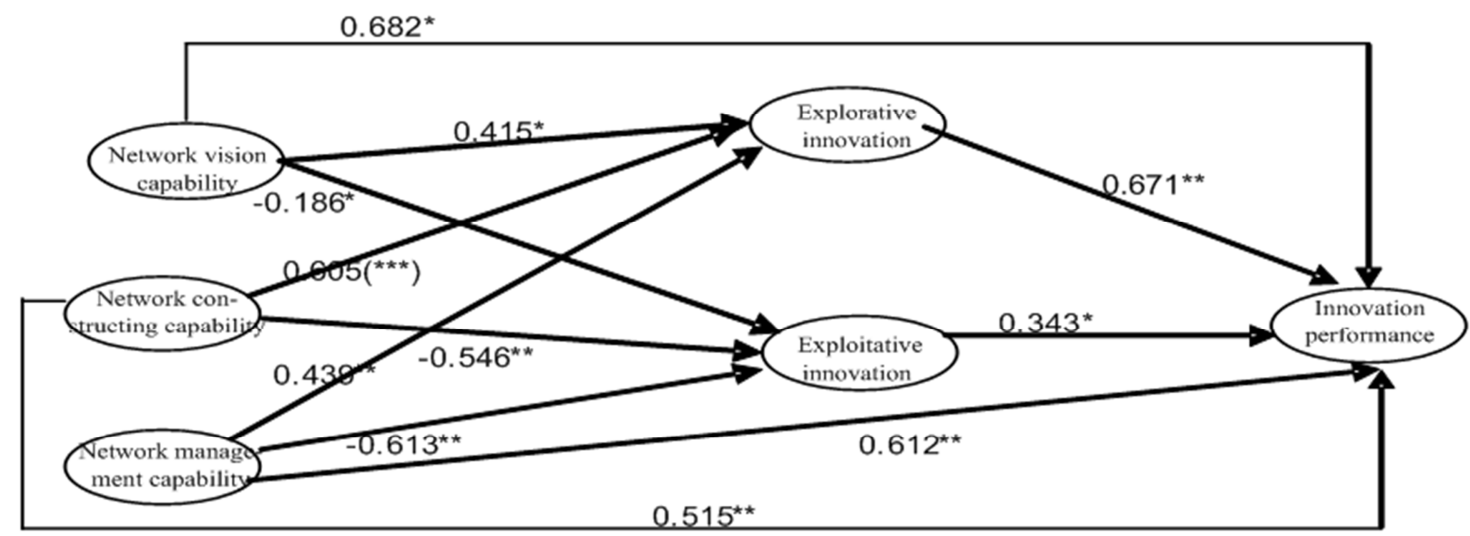

Fig. 1. Path relationship of the variables.

As can be seen from Figure 1, the standardized path coefficients of innovation performance related to network vision ability, network constructing ability, and network management capability all exceed zero, and they passed the significance test. Thus, hypotheses $1 \mathrm{a}, 1 \mathrm{~b}$, and 1c were confirmed; The influence coefficient of exploitative innovation and explorative innovation on the firm's innovation performance is positive and passed the significance test, thus hypothesis 2 is confirmed. In the relationship between network capability and innovation strategy, the influence of the three network capabilities on exploitative innovation is positive and significant, their influence on explorative innovation is negative and significant, thus hypotheses 3 and $3 \mathrm{a}$ are confirmed.

\section{Conclusion}

Based on a literature review, we propose the influence path model of network capability on the firm's innovation performance, and assume the innovation strategy form play an intermediary role, and then we verify the theoretical assumptions using the data obtained from the questionnaire. On this basis, we arrive at the following conclusions.

The exchange relationship between knowledge and operational resources in the network cannot be optimized by itself. Focal firms need to use their network management capabilities to coordinate and improve the bilateral or multilateral relationships. Although every firm in the network know that they're interdependent, and know about the importance of communication and resource sharing as well. In practice, network members tend to protect existing dedicated resources or tacit knowledge for their own interests, and they even tend to enjoy some bilateral relationships belonging to them in the network. At the same time, they also attempt to share the interests belonging to other firms. As a result, the innovation network will be inefficient and the knowledge resources will be dried up. The enhancement of the focal firm's network management capability is helpful to build a knowledge sharing platform within the network which helps to strengthen the linkage and trust relationship among partners and reduce opportunistic behavior motive and promote the sharing and transfer of knowledge among the partners. It is 
beneficial to the focal firms to discover, absorb and integrate the existing knowledge within the network. In addition, it is also beneficial to them to improve the efficiency of technology innovation using the fusion and complementation of knowledge and build the internal resource management system to support technological innovation, promote the improvement of innovation performance.

In the process of the exchange of knowledge resources and operational resources among agents in the network, network vision capability and constructing capability are beneficial to the focal firms to have a good position and priority by improving the relationship embeddness and the network's structural embeddness, so they can gain first mover advantage in technological innovation. Therefore, in order to improve the innovation performance with network resources exchange and communication opportunities, the firm should foster cooperative innovation consciousness in the organizational strategy and internal incentive system, build the behavior patterns of innovation basis by strengthening the resources and opportunities within the network environment, and develop a good capability of network awareness and recognition to achieve a first mover advantage while constructing the cooperative network. They should set up specialized agencies to create or maintain network relations and cultivate the capability of active network management cooperation, make full use of directly connected partners and the personnel in charge of external communication within the organization to expand the network, actively contact and make use of the potential collaborators possessing relationship resources, develop the organizational structure adaptable to the dynamic development, and establish the evaluation system of network management to ensure the active position in network building.

As a relatively independent element, network capability can exert a positive effect on the formation of innovation performance, and the inappropriate choice of innovation strategy within the firm will weaken this effect. In this paper, the research shows that the network capability is positively related to the exploitative innovation and negatively related to the explorative innovation, a finding consistent with that by Jansen et al. [11]. Explorative innovation regards finding new technological trajectory as the goal. It is a try of new opportunity. The exploitative innovation means the improvement of technology forms. It is based on the existing technology trajectory [14]. The network capabilities basis on which the two kinds of innovation strategy rely are of different natures. The change of firm network capability will lead to the change of communication time, emotion tightness, familiarity and reciprocity within network nodes, the impact on firm innovation will also change. With the increasing of the focal firm's network capability, trust among firms will go up as well. It is helpful for the transfer of complex knowledge or information resources, and it can promote the exploitative innovation. However, at the same time it will make the firm have a path dependence effect, thus unfavorable to the generation and transmission of differentiated information which hinders the exploratory innovation. Due to these effects, the firm can not choose the form of innovation strategy, and network capability level is an important premise of innovation strategy choice. If the firm chooses exploratory innovation strategy under the condition of strong network capability, it will not improve the innovation performance but weaken the positive effect of network capability on technology and management innovation. Similarly, in case of weak network capability, firms should avoid using the exploitative innovation strategy.

\section{References}

[1] Joe Tidd. Meeting the Innovation Challenge: Leadership for Transformation and Growth [M]. John Wiley \& Sons, 2006.

[2] Walter A, Auer M, Ritter T. The Impact of Network Capabilities and Entrepreneurial Orientation on University Spin-off Performance [J]. Journal of Business Venturing, 2006, 21 (4): 541-567.

[3] Judith Behrens. A Lack of Insight: An Experimental Analysis of R\&D Managers' Decision Making in Innovation Portfolio Management [J]. R\&D Managers' Decision Making in Innovation Portfolio Mnagement, 2016, 25(2): 239-250.

[4] Kristian Moller, Arto Rajala, Senja Svahn. Strategic Business Nets: their Type and Management [J]. Journal of Business Research, 2005, 58(3): 1274-1284.

[5] Elsebeth Holmen, Ann charlott Pedersen. Strategizing through Analyzing and Influencing The Network Horizon [J]. Industrial Marketing Management, 2003, 32(7): 409-418.

[6] Brian Uzzi. A social network's changing statistical properties and the quality of human innovation [J]. Journal of Physics A: Mathematical and Theoretical, 2008, 41(22): 481-505.

[7] Gautam Ahuja. Collaboration Networks, Structural Holes, and Innovation: A Longitudinal Study [J]. Administrative Science Quarterly, 2000, 45(3): 425-437.

[8] Ritter W.. Measuring Network Competence: Some International Evidence $[\mathrm{J}]$. The Journal of Business \& Industrial Marketing, 2002, 17(2/3): 119-138.

[9] Brass D. J., Galaskiewicz J., Greve H. R., Tsai W.. Taking Stock of Networks and Organizations: A Multilevel Perspective [J]. Academy of Management Journal, 2004, 47(2): 795-817.

[10] Stefan Kirchner. Linking institutions and firm-level outcomes: the roles of diverse innovative capability profiles in Germany's economy [J]. The European Journal of Social Science Research, 2016, (3): 462-480.

[11] Gert Human. Measuring network competence in buyer-supplier relationships [J]. South African Journal of Economic and Management Sciences, 2009, 12(4): 429-447.

[12] Ritter T., Hans George Gemünden. Inter-organizational Relationships and Networks: An Overview [J]. Journal of Business Research, 2003, 56(8): 691-697.

[13] Jansen P, Van Den Bosch J, Volberda W. Exploratory Innovation, Exploitative Innovation, and Performance: Effects of Organizational Antecedents and Environmental Moderators [J]. Management Science, 2006, 52(11): 1661-1674. 
[14] Sharon Belenzon, Mark Schankerman. Motivation and Sorting of Human Capital in Open Innovation [J]. Strategic Management Journal, 2015, 36(9): 795-820.

[15] He Z, Wong P. Exploration and exploitation: An empirical test of the ambidexterity hypothesis [J]. Organization Science, 2004, 15(4): 481-494.

[16] Benner M J, Tushman M L. Exploitation, exploration, and process management: The productivity dilemma revisited [J]. Academy of Management Review, 2003, 28(2): 238-256.

[17] Atuahene Gima K, Murray J Y. Exploratory and exploitative learning in new product development: A social capital perspective on new technology ventures in China $[\mathrm{J}]$. $\mathrm{J}$ ournal of International Marketing, 2007, 15(2):1-29.
[18] Ha Hoang, Frank T. Rothaermel. Leveraging internal and external experience: Exploration, exploitation, and R\&D project performance [J]. Strategic Management Journal, 2010, 31(7): 734-758.

[19] Juha Uotila, Markku Maula, Thomas Keil, Shaker A. Zahra. Exploration, exploitation, and financial performance: analysis of S\&P 500 corporations [J]. Strategic Management Journal, 2009, 30(2): 221-231.

[20] Koka B. R., Prescott J. E.. Designing alliance networks: The influence of network Position, environmental change, and strategy on firm Performance [J]. Strategic Management Journal, 2008, 29(6): 639-661. 